\title{
Threat level in the workplace
}

\author{
$V$ Sharmanov $^{1, *}$, Tamara Narezhnaya $^{2}$ and Artem Davydov ${ }^{3}$ \\ ${ }^{1}$ Peter the Great St. Petersburg Polytechnic University, St. Petersburg, Russia \\ ${ }^{2}$ Moscow State University of Civil Engineering, 26, Yaroslavskoye shosse, Moscow, 129337, Russia \\ ${ }^{3}$ Plekhanov Russian University of Economics, Stremyanny lane 36, Moscow, 117997, Russia
}

\begin{abstract}
The paper discusses the calculation of the indicator presented in the form of the treat level, which makes it possible to predict and characterize the emerging risk situations in the workplace. The calculation of the threat level is intended for use in assessing the organization of safe working conditions in the workplace, taking into account the labor process. The presented calculation of the threat level is universal, regardless of the type of work, the number of workers and the duration of work. The use of this indicator at enterprises will improve organizational measures to ensure safe working conditions, which will contribute to improving the quality of decisions made and prompt response to ongoing processes.
\end{abstract}

\section{Introduction}

Underestimation of hazardous situations in the workplace most often leads to the risk of injury to workers of the enterprise. Assessment of injury at workplaces is the main criterion that allows an enterprise to build organizational measures for making managerial decisions in the organization of safe working conditions, as well as in the possibility of informing employees about emerging risks.

The methods used today for assessing working conditions in workplaces are a special assessment of working conditions (SAWC), within which an assessment of the impact of hazardous and harmful production factors on an employee is applied, as well as a risk-based approach, which is a method of organizing state control. Both methods do not meet the dynamic processes of construction and installation works (CIW). When assessing the workplace, it should be possible to calculate quantitative indicators of risk situations that arise and affect the employee, taking into account the labor process, the duration of work and the number of employees working in a separate control area. At the same time, it should be easy to use and interpret the obtained results.

To reduce injuries and improve working conditions, it is necessary to identify and assess the emerging hazards and risk situations to which workers may be exposed in the workplace. In this regard, a company needs to know the weak points of its technological processes and be able to adequately assess safety when performing construction and installation work. In this case, the organization needs to classify the emerging risk situations in the production of construction and installation work, taking into account the likelihood of their occurrence.

\footnotetext{
*Corresponding author: p198320@yandex.ru
} 
Since the process of identifying emerging risks is the most important and responsible part of the risk-based approach, it is necessary to attract qualified personnel, as well as personnel who are directly related to certain types of construction and installation work that can determine the emerging risks. After identifying and classifying risks, the company needs to determine their qualitative and quantitative characteristics. Nowadays, there are a large number of risk assessment systems, but there is no single system. This makes it possible to choose from the proposed systems or develop one's own risk assessment systems.

Considering the statistics on injuries for 2019, according to the Federal Service for Labor and Employment (Rostrud), 1,613 workers died as a result of industrial accidents in companies of all types of economic activity, which is 85 less than in 2018 . According to the Social Insurance Fund of the Russian Federation (SIF RF), 35,492 insured events related to industrial injuries were registered in 2019, which exceeded the same figure for 2018 by 265 cases. [1]

One of the main factors (causes) of injuries in 2019 was the fall of a person $-33 \%$, but there is one also quite important indicator - a fall on a flat surface of the same level $-9.2 \%$. The construction industry was the most traumatic type of economic activity $-23.2 \%$. Regarding the reasons, the leaders for the causes of the accident are unsatisfactory work organization - $31.6 \%$, violation of the work schedule by the employee $-10.2 \%$, and violation of the process technology $-5.3 \%$. [1] All this clearly demonstrates the need to be vigilant in the organization of workplaces during the construction and installation work, the need to convey information about emerging hazards in the workplace to workers, and also to carry out proper work in matters of safety.

\section{Methods}

Nowadays, the occupational health and safety management systems used in companies allow preventing and reducing the development of negative scenarios that would contribute to an increase in injuries at the enterprise. These are SAWC and risk-based approach.

SAWC is a tool that focuses on the assessment of specific workplaces [2,3]. In this case, the assessment is carried out using instrumental measurements of external irritating factors that can harm the health of a potential employee. This system allows the employer to identify emerging hazardous and harmful production factors with the involvement of personnel at workplaces and to measure this influence. In relation to the periods of verification, the terms of its implementation are quite long, and in relation to the dynamics of labor processes, it is generally static. This approach to assessing the level of labor protection implies both scheduled and unscheduled inspections. The result of this assessment is a report that indicates the workplaces where a special assessment of working conditions was carried out, indicating the harmful and (or) hazardous production factors that are identified at these workplaces, prescribes measures to improve working conditions with the assignment of a risk category and subcategory to the workplace. Let's consider the situation directly at the construction site. For example, the assessment of the bricklayer's workplace is based on the severity of the labor process, i.e. it is assessed how the labor process affects its physical condition. It can be said that the occurrence of risk due to the fact that the employee may use broken tools and devices in his activities is not taken into account here.

Another tool that has been applied since 01.01.2018 is the risk-based approach. [4] Considering it, we can say that today it is the most progressive method that allows assessing not only the workplace, but also those labor processes that take place in the workplace. Here, the assessment of the influence of hazardous and harmful production factors is carried out on the basis of checklists, which contain requirements that must be 
met when performing certain labor processes in order to prevent a threat to the life and health of an employee. Checking here is only planned, others are not provided. The disadvantage is, as in the SAWC, the long terms of verification and its static nature in relation to dynamic work processes, more limited in the number of checked parameters, etc. The result of the check, as in the SAWC, is the assignment of a risk category and subcategory, but only to the enterprise [4]. It turns out that formally all workplaces and the processes that take place in these workplaces will comply with all standards, but in fact, when performing work, the same rules will be violated, which is reflected in statistical data, thereby increasing the risk of traumatic situations.

Thus, the presented systems do an excellent job each in their own information field. They are good tools for collecting and systematizing emerging hazardous and harmful production factors, as well as emerging risks in the workplace, but a common feature that allows expressing this through a single indicator is absent. There is also no possibility of predicting and developing negative situations in the dynamics of the labor process. Both approaches to assessing the level of labor protection do not take into account the likelihood and duration of the influence of hazardous and harmful production factors, risk situations, the number of workers involved in the labor process. In this regard, new approaches are needed that could be integrated into the considered systems [5-7].

One of these methods is the Fine-Kinney method $[5,8]$. This is the most common risk assessment method. The main principle is based on the assessment of emerging individual risks by the product of three characteristics (Probability, Exposure, Consequences) according to Table 1:

Table 1. $\mathrm{R}=$ Probability $\mathrm{x}$ Exposure $\mathrm{x}$ Consequences.

\begin{tabular}{|c|c|c|c|c|c|}
\hline Points & Probability & Points & Exposure & Points & Consequence \\
\hline 10 & Most likely to happen & 10 & Constantly & 100 & $\begin{array}{c}\text { Emergency situation, many } \\
\text { victims }\end{array}$ \\
\hline 6 & Very likely & 6 & $\begin{array}{l}\text { Daily during the } \\
\text { working day }\end{array}$ & 40 & Destruction, there are victims \\
\hline 3 & $\begin{array}{l}\text { Uncharacteristic, but } \\
\text { possible }\end{array}$ & 3 & Occasionally (weekly) & 15 & $\begin{array}{l}\text { Serious consequences, fatal } \\
\text { accidents }\end{array}$ \\
\hline 1 & Unlikely & 2 & Sometimes (monthly) & 7 & Disability, severe injury \\
\hline 0.5 & Hardly possible & 1 & Rarely (annually) & 3 & $\begin{array}{c}\text { Temporary incapacity for } \\
\text { work }\end{array}$ \\
\hline 0.2 & Almost impossible & 0.5 & Very rarely & 1 & $\begin{array}{l}\text { Minor trauma, first aid } \\
\text { provided }\end{array}$ \\
\hline 0.1 & Virtually impossible & & & & \\
\hline
\end{tabular}

A significant advantage is that all three parameters are expressed in terms of points, which allow easily calculating and interpreting the results obtained in accordance with Table 2 .

Table 2. The point scale for assessing the parameters of professional risk.

\begin{tabular}{|c|c|c|}
\hline Points & Risk & Preventive work \\
\hline$>320$ & Very high & Immediate termination of activities \\
\hline $160-320$ & High & Immediate improvement needed \\
\hline $70-160$ & Significant & Improvement needed \\
\hline $20-70$ & Possible & Attention should be paid \\
\hline$<20$ & Small & Subject to research \\
\hline
\end{tabular}

Risk assessment using the Fine-Kinney method allows adapting it to any type of industrial production. The main task in adaptation is to identify hazardous and harmful production factors in accordance with the technological features of production and 
integration into the existing system of labor protection control in the company. The FineKinney method is quite popular today, as indicated by a number of publications. [5, 9-12]

\section{Results and discussion}

Risk assessment in each organization can be performed according to its own developed methodology. But before proceeding with it, the company needs to determine the hazardous and harmful production factors that can cause risky situations, and also determine the likelihood of their occurrence in the dynamics of labor processes. To determine the likelihood of risk situations, statistical materials of occurrence in similar industries are used, as well as statistics within the enterprise. In this regard, each identified risk situation is assigned the probability of its occurrence according to Table 1 of the Fine-Kinney method. It is also necessary to take into account the number of people involved in the work process, and x people who can also be involved in the work process during the working day.

As the threat level, it is necessary to understand how feasible the identified risk situation, which can increase the risk of injury in the company. To assess the threat level and to interpret the results, one can use Table 2 of the Fine-Kinney method, or develop an internal assessment system in the company, reflecting the technological features of production.

The calculation of the threat level is based on the calculation of the accident rate:

$$
\mathrm{K}_{\mathrm{fj}}=\left(\mathrm{A}_{\mathrm{j}} / \mathrm{N}_{\mathrm{j}}\right) * 1000
$$

where: $\mathrm{Aj}$ - number of accidents on the $\mathrm{jth}$ site;

$\mathrm{Nj}$ - number of people on the jth site;

Since the calculation assumes data on the exact number of workers at workplaces, and the total number of workers who can be involved in the performance of work, the following designation are introduced: $\mathrm{N}_{\text {total }}{ }^{-}$the total number (involved in the performance of work during the day), then the accident rate at the checked workplace will be:

$$
\mathrm{K}_{\mathrm{fsum}}=\sum \mathrm{K}_{\mathrm{fj}} * \mathrm{~N}_{\mathrm{j}} / \mathrm{N}_{\text {total }} \text {. }
$$

In turn, $\mathbf{K}_{\mathbf{f}}$ can be represented as an index of injury rate $\mathbf{I}_{\mathbf{a}}$ expressed in assessing the impact of risk on an employee, depending on the duration of work, the number of employees, the likelihood of a hazardous factor:

$$
\mathrm{I}_{\mathrm{ai}}=\sum_{i=0}^{n} \mathrm{Pi} * \mathrm{Si}
$$

where $I_{a i}$ - average injury rate per 1000 people in 1 year; the index of injuries at a construction site is recalculated taking into account the number of employees and the duration of work;

$\mathrm{Pi}$ - frequency of accidents with the ith outcome;

$\mathrm{Si}$ - the degree of damage to a person, "damage".

Then formula 3 can be written as follows:

$$
\mathrm{I}_{\mathrm{ai} \mathrm{ji}}=* S_{i} * \mathrm{~T} * \mathrm{~N}_{\mathrm{j}} / \mathrm{N}_{\text {total }}
$$

where: $\mathrm{T}$ - time of work execution in the checked area;

Since the injury index $\mathbf{I}_{\mathbf{a}}$ can be exceeded or reduced with a certain probability (in real production conditions), then to assess this probability, the following indicators are introduced: Rprj - the risk probability expressed in points according to Table 1 of the FaineKinney method.

Thus, the calculation of the threat level $\mathrm{Rj}$ will be: 


$$
\mathrm{R}_{\mathrm{j}}=\mathrm{R}_{\mathrm{prj}} * \mathrm{~T} * \mathrm{~N}_{\mathrm{j}} / \mathrm{N}_{\text {total }}
$$

where: $\mathrm{Rj}$ - threat level in points;

Rprj - the recalculated risk probability of the j-th site to obtain the total risk probability at the construction site (probability by Fine-Kinney)

$\mathrm{T}$ - time of work performed in the checked area;

$\mathrm{Nj}$ - number of people in the checked area;

$\mathrm{N}_{\text {total }}$ - total number of people (at the facility or at a certain type of work).

Moreover, if a risk was identified, but there were no people, then the threat level is zero $\mathrm{R}_{\mathrm{j}}$. $(\mathrm{N}=0)=0$

Thus, the dependence of the influence of the number of people involved in the work and the duration of the work performed is revealed. The calculated indicators do not depend on the number of workplaces and the size of the facility, but only characterize the state of Labor Protection at the facility and indicate whether organizational and technical measures to reduce injuries are being taken.

The higher the threat level, the fewer organizational and technical measures to reduce injuries are taken. What can be detected at the facility:

- absence or inadequate training of the worker about labor safety rules;

- violation of the technological process;

- malfunction of equipment, devices and tools or its non-compliance with the conditions of the work performed;

- absence of fences, warning or prohibiting inscriptions;

- inconsistency with the work performed or careless use of the special work clothes;

- insufficient lighting;

- low level of technical production culture.

\section{Conclusions}

The presented calculation for assessing the threat level, taking into account the time of work and the number of employees who were exposed to risky situations, will make it possible to more accurately assess the situation in the workplace, as well as to increase organizational and technical measures to improve safety and reduce injuries in the company. The organization, in turn, will be able to systematize risk situations depending on technological features, to determine their likelihood of occurrence. This indicator makes it possible to quantify the situation in the workplace, which makes it possible to predict the development of injuries, and at the same time the amount of funds.

\section{References}

1. Report on the results of monitoring working conditions and labor protection in the Russian Federation in 2019 / Ministry of Labor and Social Protection of the Russian Federation, https://eisot.rosmintrud.ru/monitoring-uslovij-i-okhrany-truda

2. M.S. Baygereev, SAWC and SWOT, do not confuse, http://www.hsac.ru/news/2013/683/

3. Management of labor protection and risks in accordance with international standards, pmguinfo.dp.ua/

4. On the application of a risk-oriented approach in organizing certain types of State control (supervision) and amending some acts of the Government of the Russian Federation. Resolution of the Government of the Russian Federation of August 17, 2016 N 806 https://base.garant.ru/71473944// 
5. Havula, J., Martikainen, L., Sinelnikov, A.S., Orlova, A.V., Salamakhin, S.V. Advanced Materials Research. 2014. 945-949. Pp. 1211-1215. DOI:10.4028/www.scientific.net/AMR.945-949.1211.

6. Vedishcheva, I.S., Ananin, M.Y., Al Ali, M., Magazine of Civil Engineering. 2018. 78(2). Pp. 116-127. DOI:10.18720/MCE.78.9.

7. K. Usanova, Y.G. Barabanshchikov. Magazine of Civil Engineering. 2020. 95(3). Pp. 104-118. DOI:10.18720/MCE.95.10.

8. B.V. Sevastyanov, I.Yu. Lobova, Safety in the technosphere 1, 13-18 (2008)

9. V.V. Sharmanov, T.L. Simankina, A.E. Mamaev, Construction of unique buildings and structures 12(63) (2017)

10. Russian State Standard GOST R 58771-2019 Risk management. Risk assessment technologies, http://rdocs3.kodeks.ru/document/1200170253

11. V.V. Sharmanov, Academic Vestnik of the UralNIIproekt RAASN 3(34), 72-79 (2017)

12. Risk management - Risk assessment techniques: ISO / IEC 31010 (IEC, Geneva, 2009)

13. Yu.A. Bulavka, Life safety 7, 9-15 (2013)

14. Yu.A. Bulavka, Vestnik of Polotsk State University. Series C, Industry. Applied sciences 3, 156-163 (2013) 